\title{
Happy birthday protein kinase C: Past, present and future of a superfamily
}

\section{Birth and early years}

Protein kinase C (PKC) was born in Japan in 1977 in the Department of Biochemistry of the University of Kobe. Inoue, Kishimoto and Takai in Nishizuka's Laboratory, described in two papers in the Journal of Biological Chemistry a cyclic nucleotide-independent, proteolytically modified protein kinase from mammalian brain (named PKM, M for magnesium ions that were indispensable for activation) [1,2]. The full length enzyme [2], subsequently demonstrated to be activated by calcium and phospholipids [3], was named protein kinase $\mathrm{C}$ (C, for calcium ions, which fully activated the enzyme at low concentrations, and thus differentiate it from cyclic nucleotide-dependent kinases, protein kinase A and G). The same group observed that unsaturated diacylglycerol (DAG) was an essential activator of PKC [4], linking the previously described receptor-dependent inositol phospholipid hydrolysis [5] to protein phosphorylation, thus thrusting this enzyme into intercellular signal transduction research. PKC inhibitors were characterized in 1980 as phospholipid interfering drugs (such as chlorpromazine, imipramine and dibucaine) [6] and the first direct functional assignment for PKC was made utilizing human platelets in which the thrombininduced release of serotonin was shown to be mediated by PKC activation [7]. Starting in the early 1980s, the interest in PKC crossed Japan's borders and invaded the rest of the world, making $\mathrm{PKC}$ one of the most studied enzymes in biology, with more than 45,000 research papers published up to now.

We thus decided to celebrate the 30th birthday of PKC with a Special Issue of Pharmacological Research, reviewing the more relevant and recent developments in its characterization in physiology and pathology, highlighting the pharmacological implications and in particular the search for isozyme-selective inhibitors and activators.

It is impossible to mention all the discoveries that attracted, and still continue to attract the attention of so many scientists to this enzyme. We will concentrate just on select break-throughts that accompained PKC trentennial research and will divide this continuing story into the developments in each of the three decades (Fig. 1):

- 1977-1986: enzymatic description and modulations of activity;
- 1987-1996: isozyme identifications and their functions;

- 1997-2006: entering the "matured" age (regulation by phosphorylation) and new technological advances.

\section{The first 10 years: enzymatic description and modulations of activity}

In 1982, the observation by Castagna and colleagues that in human platelets the tumor promoting phorbol derivatives directly activate PKC, mimicking but not generating DAG (i.e. not inducing phospholipid hydrolysis) [8], opened the exciting area of research on PKC involvement in cell growth control. The same year, Kraft and coworkers reported the seminal discovery that activation with phorbol esters [9] leads to translocation (i.e. change in subcellular location) of PKC from the cell soluble to the cell particulate fraction. Radioactive phorbol 12,13 dibutyrate binding [10] was then used to localize and quantify PKC [11]. Subsequently, chronic treatment with phorbol esters was shown to down-regulate PKC phosphorylating activity [12]. The general interest in PKC culminated in a review paper on signal transduction and tumor promotion by Nishizuka, published in 1984, which became the most cited paper of the 1980s [13]. Additional inhibitors, interfering directly with PKC, were described between 1984 and 1986 and utilized extensively: the isoquinolinesulfonamide $\mathrm{H} 7$ [14], tamoxifen [15] and the anti-fungal alkaloid staurosporine [16] helped to clarify the implication of $\mathrm{PKC}$ in the regulation of several functions, including utilizing long term phorbol esters to "down regulate" the enzyme [12]. Bryostatin 1, a marine bryozoan, is an unconventional PKC activator/inhibitor; it stimulates and subsequently down-regulates PKC (like phorbol esters) but it does not act as a tumor promoter, but rather can inhibit phorbol ester effects under selected conditions [17]. The brain is the highest source for PKC in terms of catalytic activity and levels of expression [18], and one of the more exciting and intriguing aspects of PKC appears to be its involvement in the learning and memory phenomena. After the initial in vitro observation that synaptic plasticity is positively influenced by PKC activation [19] and that in vivo phorbol esters may antagonize scopolamine-induced amnesia [20], a variety of studies have accumulated providing biochemical, electrophysiological, behavioral, genetic and pharmacological evidence in favor of PKC as one of the 


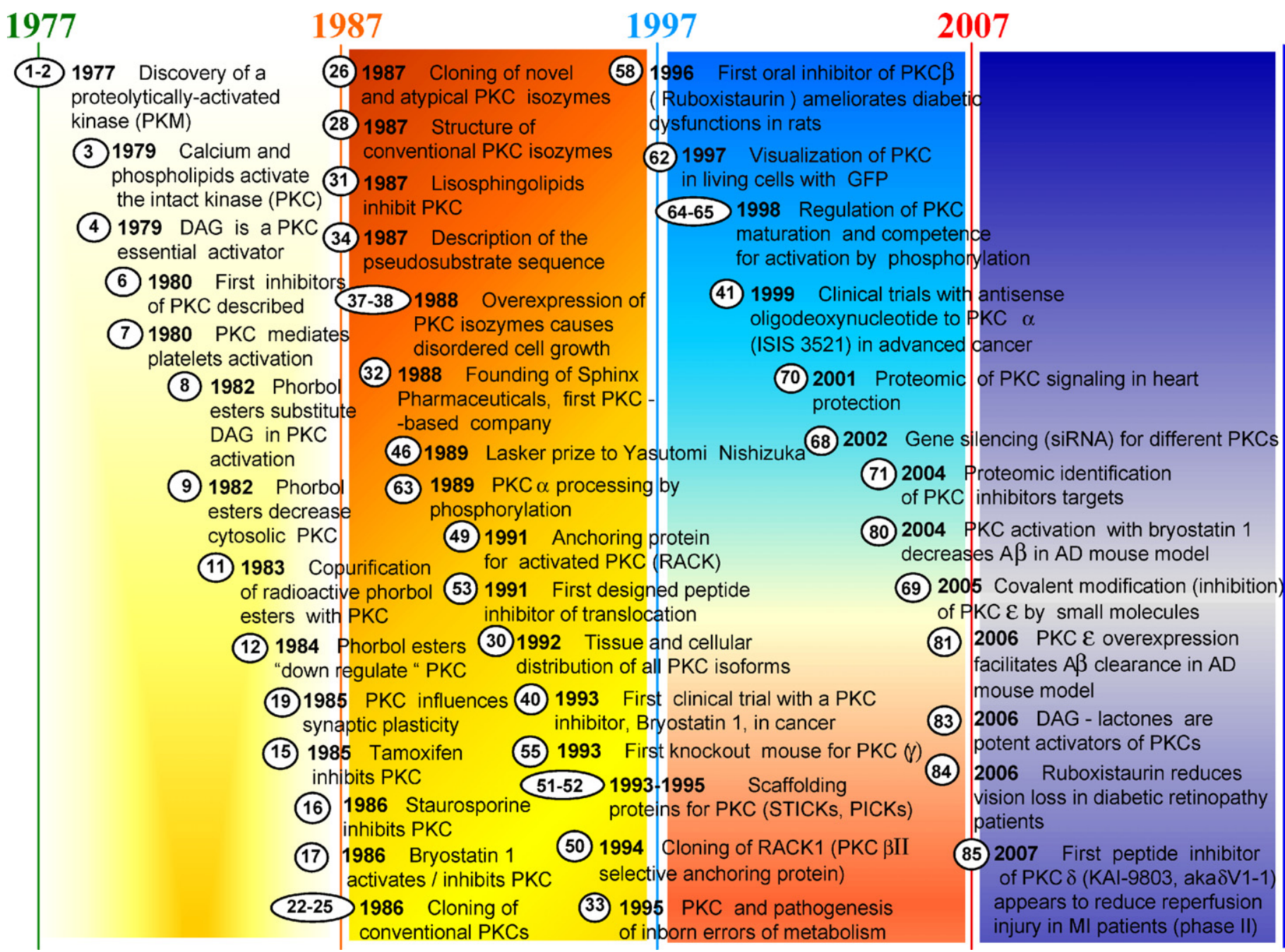





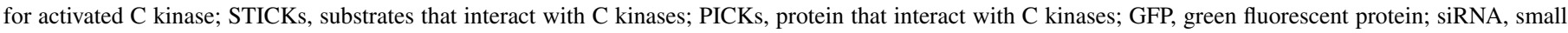
interfering RNA; $\mathrm{A} \beta$, amyloid beta peptide; $\mathrm{AD}$, Alzheimer's disease; MI, myocadial infarction.

relevant players in memory trace formation (for a review see [21]).

The PKC field began to grow in 1986, with the cloning of the calcium-dependent PKCs (or conventional, cPKCs) [22-25], and subsequently the calcium-independent PKCs (or novel, nPKCs) followed by the atypical PKCs (aPKCs) [26]. cPKCs were characterized also by chromatographic techniques, naming them as PKC-I, -II, and -III [27] (corresponding to cPKC $\gamma$, $\beta$ and $\alpha$, respectively) and consensus followed, identifying the different isozymes with greek letters.

\section{The second decade: isozyme identification and their functions}

The PKC isozymes contain conserved and variable regions in the catalytic and regulatory subunits $[28,29]$ and isozymeselective antibodies were thus produced. A detailed study on tissue and cellular distribution of all the isozymes was pub- lished in 1992 by Bill Wetsel and co-workers in Y. Hannun's laboratory [30], the same researcher who while in Bob Bell's lab characterized sphingolipids as PKC inhibitors, thus linking PKC to sphingolipidoses [31]. The involvement of different PKC isozymes in the pathogenesis of inborn errors of metabolism (sphingolipidoses, fatty acid oxidation, bile acid and cholesterol) was proposed later, in 1995 [33]. Bob Bell, whose work into diacylglycerol and PKC regulation led to the characterization of how PKC signaling is turned off, founded with Carson Loomis, in 1988 the first PKC-based Company-Sphinx Pharmaceuticals [32]. Spinx (in Research Triangle Park, NC, USA) was acquired in 1994 by Eli Lilly, leading to the discovery of the selective $\beta P K C$ oral inhibitor, ruboxistaurin (see below).

In 1987, House and Kemp described the pseudosubstrate sequence in the PKC regulatory region that is involved in intramolecular inhibitory interactions [34]. More details and updates on PKC structural composition and intramolecular regulation can be found in the opening review of this issue by 
Kheifets and Mochly-Rosen [35]. A peptide corresponding to the pseudosubstrate sequence was found to act as a selective inhibitor of PKC [34], but its use as a pharmacological agent in cells was limited because the peptide does not cross biological membranes. The search for selective pharmacological tools to specifically inhibit PKC was prompted, in part, by the findings that in addition to binding to $\mathrm{PKC}$, phorbol esters interact with other signalling molecules devoid of kinase activity such as the mammalian $\alpha$-and $\beta$-chimaerins, Ras-GRP (Ras guanylreleasing protein) and the nematode, Unc-13 (with mammalian homologues Munc 13) (more details in [36]).

Overexpression of PKC isozymes in cell cultures opened the area of research aimed at further clarifying the involvement of selected PKC isozymes in abnormal cell growth [37,38]. Further, susceptibility to transformation increased by PKC coexpression with certain oncogenes, i.e. H-ras, myc and fos [39]. These and other data eventually led to the first clinical studies in advanced cancer patients using bryostatin 1 [by CRC in Manchester, UK in 1993 [40]] and with anti-sense oligonucleotides to PKC $\alpha$ [by Isis Inc, in 1999 [41]]. Another line of research focussed on inhibiting PKC as adjuvant to improve conventional chemotherapies [42]. In spite of discouraging results, additional trials are in progress with particular attention to isozyme- and tissue-selective effects (reviewed in [43]). PKC involvement and future in tumor growth control is discussed here in two reviews. Martiny-Baron and Fabbro focus on conventional PKCs and the endpoints of all clinical trials with small molecular weight inhibitors and antisense compounds [44]. Fields and Regala concentrate on the atypical PKC $\zeta$ and $\iota$, and how $\mathrm{PKC} \mathrm{\iota}$ signalling is targeted to identify a novel drug for human lung cancer [45].

In 1989, in recognition of the contribution to the advancement of the PKC field, the Albert Lasker Basic Medical Research Prize was awarded to the "father" of this enzyme family, Yasutomi Nishizuka [46].

The regulation of PKC activation due to lipid-protein interactions was revisited following the identification of protein-protein (PKC-anchoring protein) interactions for PKC activity and function. Evidence for the presence of anchoring proteins for PKC translocation was first indicated by an in vitro study of Gopalkrishna et al. [47], showing that stable interaction of PKC with isolated plasma membranes is lost following pre-treatment of the membranes with proteases. That and the finding that individual isozymes are localized each to a unique subcellular site following activation [48] led to the discovery of Mochly-Rosen and co-workers in 1991 of PKC anchoring proteins, collectively named receptors for activated C kinases (RACKs) [49], and first designed peptide inhibitor of translocation (reviewed in [53]). The first RACK, i.e. the BIIselective RACK1, was cloned in 1994 [50]. A variety of other anchor/scaffolding proteins are known to regulate PKC homeostasis [51,52]. This research led to the development of PKC isozyme-selective peptide activators and inhibitors that induce or inhibit translocation and function of individual isozymes, respectively [53]. Budas, Churchill and Mochly-Rosen discuss the progress made in establishing cytoprotective mechanisms, which arise as a consequence of $\varepsilon \mathrm{PKC}$ activation and/or $\delta \mathrm{PKC}$ inhibition, and how these may lead to protection in the setting of myocardial ischemia reperfusion [54].

The first PKC knockout mouse was produced and characterized in 1993 and lacked the neuronal-specific cPKC $\gamma$ [55]. Data on other knockouts and transgenic mice overexpressing various PKCs have since been established and represent an intensive area of research (for a recent review see [56]). Although potential redundant roles of individual PKC isozymes complicate and limit the exact identification of isozyme-selective actions, important new information on the role of each isozyme has been described.

In addition to tumor promotion and growth, other pathologies in which abnormal PKC may be involved were recognized. These include hypertension, diabetes, atherosclerosis, to name a few, suggesting the definition of a potential "PKC syndrome" [57]. The involvement of overfunctional PKC $\beta$ in diabetes was established using a staurosporine-derivative inhibitor (i.e. LY333531 or ruboxistaurin). This orally bioavailable compound inhibits PKC $\beta$ and ameliorates different vascular dysfunctions in animal models [58]. In this volume, Das Evcimen and King discuss the essential role of PKC activation in diabetic cardioand microvascular complications, the mechanisms by which hyperglycemia causes vascular damage and summarize the clinical trials with PKC $\beta$ inhibitors in diabetic complications [59]. The importance of PKCs in respiratory physiology is covered by the contribution of Dempsey, Cool and Littler, who discuss the relevance of the bidirectional approach (inhibiting and activating different PKC isozymes) as they relate to lung pathology and highlight the differences in lung anatomy between animal models and humans [60]. The importance of PKC theta in T cell functions (activation, proliferation, differentiation and survival), but not in anti-viral responses, is reviewed by Hayashi and Altman, who provide their perspective on the potential of this isozyme as a target for controlling allergic and autoimmune diseases [61].

\section{The third decade: entering the "matured" age (regulation by phosphorylation) and new technological advances}

A diversity of functions are controlled by PKC isozymes present in the same cell. Even upon the same stimulus, individual PKCs move to different subcellular sites (membrane, organelles, cytoskeleton, nucleus) where select substrate phosphorylations leads to diverse and sometimes even opposing functions. The ability to visualize the translocation (activation) of PKC in living cells was made possible in 1997 by tagging PKC with the green fluorescent protein, GFP [62].

Although post-translational processing of PKC by phosphorylation was initially documented in tumor cells in 1989 [63], a new era in PKC regulation started in 1998, when Alexandra Newton's and Peter Parker's groups $[64,65]$ described the 
mechanisms for correct maturation and catalytic activity of PKC isozymes, requiring sequential serine/threonine phosphorylation reactions. The initial phosphorylation is common to all the isozymes and is mediated by phosphoinositide-dependent kinase 1 (PDK1), indicating a cross-talk between inositol phospholipid hydrolysis and phosphatidylinositol 3-kinase pathways, whereas the subsequent phosphorylation events are likely isozyme-specific autophosphorylations [66]. In vivo tyrosine phosphorylation, initially documented in 1993 for PKC [67], also regulates $\mathrm{PKC}$ activity in a positive or negative manner by a mechanism specific for each isozyme.

In the search for isozyme-selective PKC inhibitors, new approaches were applied including gene silencing with antisense oligonucleotides [41] and short interfering RNAs [68] as well as covalent modification of PKC isozymes with cysteinereactive peptide substrate analogs [69]. One of the most frustrating aspects in the PKC field is the difficulty in identifying selective substrates of each isozyme. A recent proteomic approach has been used to study PKC signaling in cardiac protection [70] and to identify PKC targets [71]. In another contribution, Agnetti et al. [72] discuss the technologies and applications of proteomics to the study of kinases, in general, and PKC-mediated phosphorylation of cytoskeletal, myofilament and mitochondrial proteins in heart failure, hypertrophy and cardioprotection, in particular.

The involvement of PKC isozymes in the function and pathologies of the central nervous system is another area of intense research and therapeutic prospect. This special issue covers three potential therapeutic indications for PKC regulating drugs. These include: ethanol addiction, pain and aging. Newton and Ron summarize data on acute and chronic ethanol effects on PKC isozymes underlining the role of select isozymes as potential therapeutic targets for alcoholism [73]. How PKC may function as a relevant regulator of peripheral and central sensitization that underlies many chronic pain conditions is reviewed by Velázquez, Mohammad and Sweitzer [74]. Finally, soon after PKC involvement in learning and memory had been recognized, its role in physiological and pathological brain aging has been a focus of reseach (reviewed in [75]). An age- and pathologyrelated (Alzheimer's disease) deficit in PKC activation and anchoring, rather than changes in isozyme levels, seem to be the most consistent finding, also in non-neuronal tissues [76]. These aspects together with emerging concepts on PKC-dependent mRNA stabilization related to memory substates [77] are sumarized in the review by Pascale et al. [78], suggesting that PKC activation could be a useful approach to correct these deficits.

It is possible that the potential of PKC activators as therapeutic compounds may be limited by their tumor promoting actions. However, there are drug candidates, such as bryostatin 1 , that activate PKC but are devoid of tumor promoting effects [79]. Furthermore, isozyme-selective activator peptides, targeting PKC isozymes that are not related to uncontrolled growth, have also been identified [53]. Such selective activators may provide benefits for patients with Alzheimer's disease (AD), in which PKC appears to act both upstream and downstream of beta amyloid $(A \beta)$ accumulation in brain tissues. For example, PKC activation with bryostatin 1 decreased $A \beta$ brain deposition in mouse models of $\mathrm{AD}$ favoring non-amyloidogenic metabolism of the $\mathrm{A} \beta$ precursor [80] and $\mathrm{PKC} \varepsilon$ activation decreased brain $A \beta$ accumulation, favoring its clearance [81]. A general outline of PKC therapeutic potential in AD can be found in a recent publication [82]. In addition to isozyme-selective peptide activators [53], PKC activators belonging to the DAG-lactone chemical structure are also promising compounds for activating specific $\mathrm{PKC}$ isozymes [83].

\section{The coming years: can PKC go from bench to bedside?}

While research on PKC continues to attract interest in the basic research community, applications of $\mathrm{PKC}$ regulating drugs has met limited success. PKC $\alpha$ and PKC $\varepsilon$ inhibitors may be useful to inhibit tumor growth and multi-drug resistance. The cardiovascular field is concentrating on $\beta$ - and $\delta$-PKC inhibitors and clinical studies have given some hope for approaching diabetic complications such as retinopathy with ruboxistaurin [84] and with a PKC $\delta$ inhibitor peptide for acute myocardial infarction. Data from a phase IIa safety and dose escalation clinical trial of KAI Pharmaceuticals indicates that the peptide inhibitor of $\delta \mathrm{PKC}$ appears safe and may provide protection from reperfusion injury when given for patients immediately after acute myocardial infarction [85]. Meanwhile, the concept of "PKC activation" has recently found preclinical support in terms of limiting cardiac and brain degeneration. In this case, $\mathrm{PKC} \varepsilon$ activation could be a good candidate for clinical trials. Finally, promising preclinical work regarding regulation of immune response, alcoholism and possibly other addictions, pain sensation and other clinically relevant conditions suggest that we will see a new surge in drug development that focuses on PKC in the coming years. We hope that this Special Issue will encourage further research in the PKC field that will yield novel drugs for treatment of human diseases.

\section{Disclosure}

DM-R is the founder and member of the board of KAI Pharmaceuticals. However, none of the work in her lab is supported by or is in collaboration with the company.

\section{Acknowledgements}

FB is supported by the grant from Italian Ministero Sanità/Regione Lazio (Progetto Alzheimer); DM-R is supported in part by NIG grants HL 52141, AA 11147, HL 76674 and NS 44350 .

\section{References}

[1] Takai Y, Kishimoto A, Inoue M, Nishizuka Y. Studies on a cyclic nucleotide-independent protein kinase and its proenzyme in mammalian tissues. I. Purification and characterization of an active enzyme from bovine cerebellum. J Biol Chem 1977;252:7603-9. 
[2] Inoue M, Kishimoto A, Takai Y, Nishizuka Y. Studies on a cyclic nucleotide-independent protein kinase and its proenzyme in mammalian tissues. II. Proenzyme and its activation by calcium-dependent protease from rat brain. J Biol Chem 1977;252:7610-6

[3] Takai Y, Kishimoto A, Iwasa Y, Kawahara Y, Mori T, Nishizuka Y. Calciumdependent activation of a multifunctional protein kinase by membrane phospholipids. J Biol Chem 1979;254:3692-5.

[4] Takai Y, Kishimoto A, Kikkawa U, Mori T, Nishizuka Y. Unsaturated diacylglycerol as a possible messenger for the activation of calcium-activated, phospholipid-dependent protein kinase system. Biochem Biophys Res Commun 1979;91:1218-24.

[5] Hokin MR, Hokin LE. Enzyme secretion and the incorporation of P32 into phospholipids of pancreas slices. J Biol Chem 1953;203:967-77.

[6] Mori T, Takai Y, Minakuchi R, Yu B, Nishizuka Y. Inhibitory action of chlorpromazine, dibucaine, and other phospholipid-interacting drugs on calcium-activated, phospholipid-dependent protein kinase. J Biol Chem 1980;255:8378-80.

[7] Kawahara Y, Takai Y, Minakuchi R, Sano K, Nishizuka Y. Phospholipid turnover as a possible transmembrane signal for protein phosphorylation during human platelet activation by thrombin. Biochem Biophys Res Commun 1980;97:309-17.

[8] Castagna M, Takai Y, Kaibuchi K, Sano K, Kikkawa U, Nishizuka Y. Direct activation of calcium-activated, phospholipid-dependent protein kinase by tumor-promoting phorbol esters. J Biol Chem 1982;257:7847-51.

[9] Kraft AS, Anderson WB, Cooper HL, Sando JJ. Decrease in cytosolic calcium/phospholipid-dependent protein kinase activity following phorbol ester treatment of EL4 thymoma cells. J Biol Chem 1982;257: 13193-6.

[10] Driedger PE, Blumberg PM. Specific binding of phorbol ester tumor promoters. Proc Natl Acad Sci USA 1980;77:567-71.

[11] Niedel JE, Kuhn LJ, Vandenbark GR. Phorbol diester receptor copurifies with protein kinase C. Proc Natl Acad Sci USA 1983;80:36-40.

[12] Rodriguez-Pena A, Rozengurt E. Disappearance of $\mathrm{Ca}^{2+}$-sensitive, phospholipid-dependent protein kinase activity in phorbol ester-treated 3T3 cells. Biochem Biophys Res Commun 1984;120:1053-9.

[13] Nishizuka Y. The role of protein kinase $C$ in cell surface signal transduction and tumour promotion. Nature 1984;308:693-8.

[14] Hidaka H, Inagaki M, Kawamoto S, Sasaki Y. Isoquinolinesulfonamides, novel and potent inhibitors of cyclic nucleotide dependent protein kinase and protein kinase C. Biochemistry 1984;23:5036-41.

[15] O'Brian CA, Liskamp RM, Solomon DH, Weinstein IB. Inhibition of protein kinase C by tamoxifen. Cancer Res 1985;45:2462-5.

[16] Tamaoki T, Nomoto H, Takahashi I, Kato Y, Morimoto M, Tomita F Staurosporine, a potent inhibitor of phospholipid/ $\mathrm{Ca}^{2+}$ dependent protein kinase. Biochem Biophys Res Commun 1986;135:397-402.

[17] Kraft A, Smith S, Berkow JB, Bryostatin RL. an activator of the calcium phospholipid-dependent protein kinase, blocks phorbol ester-induced differentiation of human promyelocytic leukemia cells HL-60. Proc Natl Acad Sci USA 1986;83:1334-8.

[18] Nishizuka Y. The molecular heterogeneity of protein kinase C and its implications for cellular regulation. Nature 1988;334:661-5.

[19] Routtenberg A. Phosphoprotein regulation of memory formation: enhancement and control of synaptic plasticity by protein kinase $\mathrm{C}$ and protein $\mathrm{F} 1$ Ann N Y Acad Sci 1985;444:203-11.

[20] Laborit H, Zerbib R. Action of PMA (phorbol myristate acetate), scopolamine, propranolol, and oxotremorine on memorization of an active or passive avoidance test. Encephale 1989;15:29-35.

[21] Micheau J, Riedel G. Protein kinases: which one is the memory molecule? Cell Mol Life Sci 1999;55:534-48.

[22] Coussens L, Parker PJ, Rhee L, Yang-Feng TL, Chen E, Waterfield MD, et al. Multiple, distinct forms of bovine and human protein kinase $\mathrm{C}$ suggest diversity in cellular signaling pathways. Science 1986;233:859-66.

[23] Parker PJ, Coussens L, Totty N, Rhee L, Young S, Chen E, et al. The complete primary structure of protein kinase $\mathrm{C}$ - the major phorbol ester receptor. Science 1986;233:853-9.

[24] Knopf JL, Lee MH, Sultzman LA, Kriz RW, Loomis CR, Hewick RM, et al. Cloning and expression of multiple protein kinase $\mathrm{C}$ cDNAs. Cell 1986;46:491-502.
[25] Ono Y, Kurokawa T, Fujii T, Kawahara K, Igarashi K, Kikkawa U, et al. Two types of complementary DNAs of rat brain protein kinase C. Heterogeneity determined by alternative splicing. FEBS Lett 1986;206:347-52.

[26] Ono Y, Fujii T, Ogita K, Kikkawa U, Igarashi K, Nishizuka Y. Identification of three additional members of rat protein kinase $\mathrm{C}$ family: delta-, epsilonand zeta-subspecies. FEBS Lett 1987;226:125-8.

[27] Huang KP, Nakabayashi H, Huang FL. Isozymic forms of rat brain $\mathrm{Ca}^{2+}$ activated and phospholipid-dependent protein kinase. Proc Natl Acad Sci USA 1986;83:8535-9.

[28] Kikkawa U, Ono Y, Ogita K, Fujii T, Asaoka Y, Sekiguchi K, et al. Identification of the structures of multiple subspecies of protein kinase $\mathrm{C}$ expressed in rat brain. FEBS Lett 1987;217:227-31

[29] Ono Y, Fujii T, Ogita K, Kikkawa U, Igarashi K, Nishizuka Y. The structure, expression, and properties of additional members of the protein kinase $\mathrm{C}$ family. J Biol Chem 1988;263:6927-32.

[30] Wetsel WC, Khan WA, Merchenthaler I, Rivera H, Halpern AE, Phung $\mathrm{HM}$, et al. Tissue and cellular distribution of the extended family of protein kinase C isoenzymes. J Cell Biol 1992;117:121-33.

[31] Hannun YA, Bell RM. Lysosphingolipids inhibit protein kinase C: implications for the sphingolipidoses. Science 1987;235:70-4.

[32] http://www.intersouth.com/success/sphinx.aspx.

[33] Boneh A. Possible role for protein kinase $\mathrm{C}$ in the pathogenesis of inborn errors of metabolism. J Cell Biochem 1995;59:27-32.

[34] House C, Kemp BE. Protein kinase C contains a pseudosubstrate prototope in its regulatory domain. Science 1987;238:1726-8.

[35] Kheifets V, Mochly-Rosen D. Insight into intra- and inter-molecular interactions of PKC: design of specific modulators of kinase function. Pharmacol Res 2007;55:467-76.

[36] Ron D, Kazanietz MG. New insights into the regulation of protein kinase C and novel phorbol ester receptors. FASEB J 1999;13:1658-76.

[37] Housey GM, Johnson MD, Hsiao WL, O'Brian CA, Murphy JP, Kirschmeier $\mathrm{P}$, et al. Overproduction of protein kinase $\mathrm{C}$ causes disordered growth control in rat fibroblasts. Cell 1988;52:343-54.

[38] Persons DA, Wilkison WO, Bell RM, Finn OJ. Altered growth regulation and enhanced tumorigenicity of NIH $3 \mathrm{~T} 3$ fibroblasts transfected with protein kinase C-I cDNA. Cell 1988;52:447-58.

[39] Weinstein IB. Nonmutagenic mechanisms in carcinogenesis: role of protein kinase $\mathrm{C}$ in signal transduction and growth control. Environ Health Perspect 1991;93:175-9.

[40] Prendiville J, Crowther D, Thatcher N, Woll PJ, Fox BW, McGown A, et al. A phase I study of intravenous bryostatin 1 in patients with advanced cancer. Br J Cancer 1993;68:418-24.

[41] Nemunaitis J, Holmlund JT, Kraynak M, Richards D, Bruce J, Ognoskie N, et al. Phase I evaluation of ISIS 3521, an antisense oligodeoxynucleotide to protein kinase $\mathrm{C}$-alpha, in patients with advanced cancer. J Clin Oncol 1999; 17:3586-95.

[42] Lorenzo PS, Dennis PA. Modulating protein kinase C (PKC) to increase the efficacy of chemotherapy: stepping into darkness. Drug Resist Updat 2003;6:329-39.

[43] Hofmann J. Protein kinase C isozymes as potential targets for anticancer therapy. Curr Cancer Drug Targets 2004;4:125-46.

[44] Martiny-Baron G, Fabbro D. Classical PKC isoforms in cancer. Pharmacol Res 2007;55:477-86.

[45] Fields AP, Regala RP. Protein kinase C iota: human oncogene, prognostic marker and therapeutic target. Pharmacol Res 2007;55:487-97.

[46] Nishizuka Y. The Albert Lasker Medical Awards. The family of protein kinase C for signal transduction. JAMA 1989;262:1826-33.

[47] Gopalakrishna R, Barsky SH, Thomas TP, Anderson WB. Factors influencing chelator-stable, detergent-extractable, phorbol diester-induced membrane association of protein kinase C. Differences between $\mathrm{Ca}^{2+}$. induced and phorbol ester-stabilized membrane bindings of protein kinase C. J Biol Chem 1986;261:16438-45.

[48] Mochly-Rosen D, Henrich CJ, Cheever L, Khaner H, Simpson PC. A protein kinase $\mathrm{C}$ isozyme is translocated to cytoskeletal elements on activation. Cell Regul 1990;1:693-706.

[49] Mochly-Rosen D, Khaner H, Lopez J. Identification of intracellular receptor proteins for activated protein kinase C. Proc Natl Acad Sci USA 1991;88:3997-4000. 
[50] Ron D, Chen CH, Caldwell J, Jamieson L, Orr E, Mochly-Rosen D. Cloning of an intracellular receptor for protein kinase C: a homolog of the beta subunit of G proteins. Proc Natl Acad Sci USA 1994;91:839-43 [Erratum in: Proc Natl Acad Sci USA 1995;92:2016].

[51] Chapline C, Ramsay K, Klauck T, Jaken S. Interaction cloning of protein kinase C substrates. J Biol Chem 1993;268:6858-61.

[52] Staudinger J, Zhou J, Burgess R, Elledge SJ, Olson EN. PICK1: a perinuclear binding protein and substrate for protein kinase $\mathrm{C}$ isolated by the yeast two-hybrid system. J Cell Biol 1995;128:263-71.

[53] Souroujon MC, Mochly-Rosen D. Peptide modulators of protein-protein interactions in intracellular signaling. Nat Biotechnol 1998;16:919-24.

[54] Budas GR, Churchill EN, Mochly-Rosen D. Cardioprotective mechanisms of PKC-isozyme selective activators and inhibitors in the treatment of ischemia-reperfusion injury. Pharmacol Res 2007;55:523-36.

[55] Abeliovich A, Chen C, Goda Y, Silva AJ, Stevens CF, Tonegawa S. Modified hippocampal long-term potentiation in PKC gamma-mutant mice. Cell 1993;75:1253-62.

[56] Choi DS, Messing RO. Animal models in the study of protein kinase C isozymes. Methods Mol Biol 2003;233:455-73.

[57] McCarty MF. Up-regulation of intracellular signalling pathways may play a central pathogenic role in hypertension, atherogenesis, insulin resistance, and cancer promotion: the 'PKC syndrome'. Med Hypotheses 1996;46:191-221.

[58] Ishii H, Jirousek MR, Koya D, Takagi C, Xia P, Clermont A, et al. Amelioration of vascular dysfunctions in diabetic rats by an oral PKC beta inhibitor. Science 1996;272:728-31.

[59] Das Evcimen N, King GL. The role of protein kinase C activation and the vascular complications of diabetes. Pharmacol Res 2007;55:498-510.

[60] Dempsey EC, Littler CM. Lung disease and PKCs. Pharmacol Res 2007;55:545-59.

[61] Hayashi K, Altman A. Protein kinase C theta (PKC $\theta)$ : a key player in $\mathrm{T}$ cell life and death. Pharmacol Res 2007;55:537-44.

[62] Sakai N, Sasaki K, Ikegaki N, Shirai Y, Ono Y, Saito N. Direct visualization of the translocation of the gamma-subspecies of protein kinase $\mathrm{C}$ in living cells using fusion proteins with green fluorescent protein. J Cell Biol 1997;139:1465-76.

[63] Borner C, Filipuzzi I, Wartmann M, Eppenberger U, Fabbro D. Biosynthesis and posttranslational modifications of protein kinase $\mathrm{C}$ in human breast cancer cells. J Biol Chem 1989;264:13902-9.

[64] Le Good JA, Ziegler WH, Parekh DB, Alessi DR, Cohen P, Parker PJ. Protein kinase $\mathrm{C}$ isotypes controlled by phosphoinositide 3-kinase through the protein kinase PDK1. Science 1998;281:2042-5.

[65] Dutil EM, Toker A, Newton AC. Regulation of conventional protein kinase $\mathrm{C}$ isozymes by phosphoinositide-dependent kinase 1 (PDK-1). Curr Biol 1998;8:1366-75.

[66] Toker A, Cantley LC. Signalling through the lipid products of phosphoinositide-3-OH kinase. Nature 1997;387:673-6.

[67] Denning MF, Dlugosz AA, Howett MK, Yuspa SH. Expression of an oncogenic rasHa gene in murine keratinocytes induces tyrosine phosphorylation and reduced activity of protein kinase $\mathrm{C}$ delta. J Biol Chem 1993;268:26079-81.

[68] Irie N, Sakai N, Ueyama T, Kajimoto T, Shirai Y, Saito N. Subtype- and species-specific knockdown of PKC using short interfering RNA. Biochem Biophys Res Commun 2002;298:738-43.

[69] Chu F, Koomen JM, Kobayashi R, O'Brian CA. Identification of an inactivating cysteine switch in protein kinase Cepsilon, a rational target for the design of protein kinase Cepsilon-inhibitory cancer therapeutics. Cancer Res 2005;65:10478-85.

[70] Ping P, Zhang J, Pierce Jr WM, Bolli R. Functional proteomic analysis of protein kinase $\mathrm{C}$ epsilon signaling complexes in the normal heart and during cardioprotection. Circ Res 2001;88:59-62.

[71] Brehmer D, Godl K, Zech B, Wissing J, Daub H. Proteome-wide identification of cellular targets affected by bisindolylmaleimide-type protein kinase C inhibitors. Mol Cell Proteomics 2004:3:490-500.
[72] Agnetti G, Kane LA, Guarnieri C, Caldarera CM, Van Eyk JE. Proteomic technologies in the study of kinases: Novel tools for the investigation of PKC in the heart. Pharmacol Res 2007;55:511-22.

[73] Newton PN, Ron D. PKC and Alcohol addiction. Pharmacol Res 2007;55:570-7.

[74] Velázquez KT, Mohammad H, Sweitzer SM. Protein kinase $\mathrm{C}$ in pain: Involvement of multiple isoforms. Pharmacol Res 2007;55:578-89.

[75] Battaini F, Pascale A, Paoletti R, Govoni S. The role of anchoring protein RACK1 in PKC activation in the ageing rat brain. Trends Neurosci 1997;20:410-5.

[76] Battaini F, Pascale A. Protein kinase C signal transduction regulation in physiological and pathological aging. Ann N Y Acad Sci 2005;1057:177-92.

[77] Amadio M, Battaini F, Pascale A. The different facets of protein kinases C: old and new players in neuronal signal transduction pathways. Pharmacol Res 2006;54:317-22.

[78] Pascale A, Amadio M, Govoni S, Battaini F. The aging brain, a target for the future: the protein kinase C involvement. Pharmacol Res 2007;55: $560-9$.

[79] Sun MK, Alkon DL. Bryostatin-1: pharmacology and therapeutic potential as a CNS drug. CNS Drug Rev 2006;12:1-8.

[80] Etcheberrigaray R, Tan M, Dewachter I, Kuiperi C, Van der Auwera I, Wera S, et al. Therapeutic effects of PKC activators in Alzheimer's disease transgenic mice. Proc Natl Acad Sci USA 2004;101:11141-6.

[81] Choi DS, Wang D, Yu GQ, Zhu G, Kharazia VN, Paredes JP, et al. PKCepsilon increases endothelin converting enzyme activity and reduces amyloid plaque pathology in transgenic mice. Proc Natl Acad Sci USA 2006;103:8215-20.

[82] Alkon DL, Sun MK, Nelson TJ. PKC signaling deficits: a mechanistic hypothesis for the origins of Alzheimer's disease. Trends Pharmacol Sci 2007;28:51-60.

[83] Lee J, Kang JH, Han KC, Kim Y, Kim SY, Youn HS, et al. Branched diacylglycerol-lactones as potent protein kinase $\mathrm{C}$ ligands and alphasecretase activators. J Med Chem 2006;49:2028.

[84] PKC-DRS2 Group; Aiello LP, Davis MD, Girach A, Kles KA, Milton RC, Sheetz MJ, et al. Effect of ruboxistaurin on visual loss in patients with diabetic retinopathy. Ophthalmology 2006;113:2221-30.

[85] Roe MT, et al. Targeted inhibition of delta-protein kinase C to ameliorate reperfusion injury during primary percutaneous coronary intervention for acute ST-elevation myocardial infarction: results from the DELTA MI trial. In: American College of Cardiology 56th annual scientific session, i2 summit 2007 (innovation in intervention). Late-breaking clinical trials II, session 2405. 2007.

Guest Editor

Fiorenzo Battaini*

Department of Neurosciences, Section on Pharmacology, University of Roma “Tor Vergata”, School of Medicine, Roma, Italy

Guest Editor

Daria Mochly-Rosen

Department of Chemical and Systems Biology, Stanford University School of Medicine, Stanford, CA, USA

* Corresponding author.

FB dedicates this issue to the memory of his parents, Giuseppina Rossi and Gaetano Battaini, for their encouragement to pursue the exciting career in science. E-mail address: battaini@med.uniroma2.it

(F. Battaini) 